\title{
Facial-affective communication and verbal relational offers during ruptures and resolution strategies: A systematic single case study*
}

Comunicación facial-afectiva y ofertas relacionales verbales durante rupturas y estrategias de resolución: Un estudio sistemático de caso único

\author{
Carolina Altimir ${ }^{1} \underline{\mathrm{ORCID}}$, Nelson Valdés-Sánchez $z^{2} \underline{\mathrm{ORCID}}$ \\ ' Universidad Alberto Hurtado \\ ${ }^{2}$ Universidad Santo Tomás \\ 12 Millennium Institute for Research on Depression and Personality (MIDAP) \\ ${ }^{12}$ Center for Research in Psychotherapy (CIPsi) \\ Chile
}

Fecha correspondencia:

Received: december 9, 2019

Accepted: september 30, 2020.

Forma de citar:

Altimir, C., \& Valdés-Sánchez,

N. (2020). Facial-affective

communication and verbal

relational offers during ruptures

and resolution strategies: A

systematic single case study. Rev.

CES PSico, 13(3), 180-200.

\section{Open access}

(c) Copyright

Licencia creative commons

Etica de publicaciones

Revisión por pares

Gestión por Open Journal System

DOI: http://dx.doi.org/10.21615/

cesp.13.3.11

Comparte

\section{Abstract}

Research on the therapeutic relationship has underscored its central role for the therapeutic change process, indicating the relevance of determining the specific elements and mechanisms involved in its configuration (Knobloch-Fedders, Elkin, \& Kiesler, 2014). Research on ruptures of the therapeutic relationship has yielded particular contributions to better understanding the interpersonal negotiation process involved in the patient-therapist interaction. Although previous studies have contributed to the objective characterization and the exhaustive description of ruptures, more research is needed to further specify markers that allow a better understanding about how patterns of affective regulation between patient and therapist are involved and contribute to the emergence of these events and the attempts at reparation. The aim of this study is to characterize patient's and therapist's facial-affective behavior associated to verbal relational offers (RO) during rupture (R) and resolution strategy (RS) events in a brief psychodynamic therapy. Facial-affective behavior was determined using the Facial Action Coding System (FACS), ROs were derived from the content analysis of session transcripts, and R and RS were determined using the 3RS. Nested analyses were carried to establish associations between variables. Results indicate characteristic patient-therapist facial-verbal regulatory patterns for both rupture and resolution strategy events. These findings underscore the value of combining multiple approaches to allow an access to observable indicators of dyadic affect regulatory processes that can contribute to better understand and be attentive to the oscillations of the therapeutic relationship. 
ISSN: 2011-3080

Sobre el artículo:

*Acknowledgements: This study was supported by ANID (National Research and Development Agency), FONDECYT Project N ${ }^{\circ}$ 11180671, and the ANID Millennium Science Initiative /Millennium Institute for Research on Depression and Personality-MIDAP, MIDAP ICS13 005.

\section{Sobre los autores:}

1. PhD in Psychotherapy. Assistant Professor at Faculty of Psychology Universidad Alberto Hurtado, Adjunct Researcher at the Millennium Institute for Research on Depression and Personality (MIDAP), Adjunct Assistant Professor at the Pontificia Universidad Católica de Chile. Director of Psychotherapy and Change - Red Latinoamericana de Investigación en Psicoterapia, Deputy-director at the Center for Research in Psychotherapy (CIPsi). Member of the Society for Psychotherapy Research (SPR)).

2. PhD in Psychotherapy. Professor at the Psychology Department, Universidad Santo Tomás (UST), Santiago, Chile. Adjunct Researcher at the Millennium Institute for Research on Depression and Personality (MIDAP). Researcher at the Center for Research in Psychotherapy (CIPsi). Member of the Scientific Society of Psychology (SCP) and the Society for Psychotherapy Research (SPR).
Keywords: Ruptures, Resolutions, Facial-Affective Communication, Relational Offers, Psychotherapeutic Process, Therapeutic Alliance.

\section{Resumen}

La investigación sobre la relación terapéutica ha subrayado su papel central en el proceso de cambio terapéutico, indicando la relevancia de determinar los elementos y mecanismos específicos que intervienen en su configuración (Knobloch-Fedders, Elkin, \& Kiesler, 2014). La investigación sobre las rupturas de la relación terapéutica ha aportado a la comprensión del proceso de negociación interpersonal que interviene en la interacción paciente-terapeuta. Aunque estudios anteriores han contribuido a la caracterización objetiva y exhaustiva de las rupturas, se necesitan más investigaciones para especificar los marcadores que permiten comprender el modo como los patrones de regulación afectiva entre paciente y terapeuta están involucrados y contribuyen a la generación de estos eventos y a los intentos de reparación. El objetivo de este estudio es caracterizar el comportamiento facial-afectivo de paciente y terapeuta asociado a las ofertas relacionales (OR) verbales durante los eventos de ruptura (R) y de estrategia de resolución (ER) en una terapia psicodinámica breve. El comportamiento afectivo facial se determinó usando el Facial Action Coding System (FACS), las ORs se derivaron del análisis del contenido de las transcripciones de sesiones, y las $\mathrm{R}$ y ER se determinaron usando el 3RS. Se realizaron análisis anidados para establecer asociaciones entre las variables. Los resultados indican la presencia de pautas regulatorias faciales-verbales entre paciente y terapeuta características de las rupturas y estrategias de resolución; y señalan el valor de combinar múltiples enfoques para permitir el acceso a indicadores observables de los procesos regulatorios diádicos que contribuyen a comprender y atender las oscilaciones de la relación terapéutica.

Palabras clave: Rupturas, Resoluciones, Comunicación Afectivo-Facial, Ofertas Relacionales, Proceso Psicoterapéutico, Alianza Terapéutica.

\section{Introduction}

Psychotherapy process research has pointed to the therapeutic relationship as a central element of the therapeutic change process (Horvath, Del Re, Flückiger, \& Symonds, 2011; Norcross, 2011), and a renewed interest has been posed in the field to determine specific elements and mechanisms involved in its configuration (Knobloch-Fedders, Elkin, \& Kiesler, 2014). In an attempt to specify these elements, Safran and Muran (2000) envision the therapeutic relationship as a process that implicates a continuous -conscious and unconscious-, negotiation between patient and therapist subjectivities which involves tensions that are relevant for the therapy process. These tensions are manifested in relationship ruptures (Safran, 2003), understood as interpersonal stressful events that challenge the stability of the relationship (Eubanks, Muran, \& Safran, 2015), as they imply a temporary deterioration of the communicative process and a breakdown of the collaboration between patient and therapist (Safran, \& Muran, 2006).

According to the authors, ruptures involve the activation of dysfunctional relational patterns commanded by the participants' relational schemes (Safran \& Kraus, 2014). According to the patient's particular relational scheme activated, Safran and Muran (2000) have observed that ruptures can be expressed either as a withdrawal or emotional disengagement from the therapist, or from some aspect of the therapy process; or as a confrontation, where the patient expresses dissatisfaction in a non-collaborative way, or attempts to control the therapist. In response to ruptures, therapists 
Pág 182

Research on facial-affective behavior in psychotherapy is another line of process research that has contributed to understanding the way in which the therapeutic relationship is shaped. Their assumption is that affective processes play a central role in developing, maintaining, and regulating the therapeutic relationship (Benecke, Peham, \& Bänninger-Huber, 2005). can initiate resolution strategies, which include a metacommunication of the interactional process, the exploration of the patient's covert emotional states, or the clarification of misunderstandings (Eubanks et al., 2015).

The relevance of studying ruptures is based on research that indicates that a poor resolution of these events is associated with the repetition, within the therapeutic relationship, of the patient's dysfunctional interpersonal cycle (Coutinho, Ribeiro, Hill, \& Safran, 2011), and of ineffective interventions by the therapist (Castonguay, Goldfried, Wiser, Raue, \& Hayes, 1996; Piper, Azin, Joyce, \& McCallum, 1991). Specifically, an association between the repeated presence of unresolved confrontation ruptures and premature dropout has been observed (Coutinho et al., 2011; Coutinho, Ribeiro, Fernandes, Sousa, \& Safran, 2014; Tryon, \& Kane, 1995). Meanwhile, an adequate approach and timely resolution of ruptures is associated to therapeutic change, as it allows the patient to explore, challenge, and eventually modify maladaptive interpersonal patterns (Safran, Muran, Samstag, \& Winston, 2005).

Research on facial-affective behavior in psychotherapy is another line of process research that has contributed to understanding the way in which the therapeutic relationship is shaped. Their assumption is that affective processes play a central role in developing, maintaining, and regulating the therapeutic relationship (Benecke, Peham, \& Bänninger-Huber, 2005). Their research supports the notion that relevant instances of the therapeutic exchange trigger varying degrees of emotional dysregulation in the participants, with their concomitant attempts to self- and interactively regulate their affective states, which are expressed both verbally and non-verbally (Bänninger-Huber, 1992; Bänninger-Huber, \& Widmer, 1999; Benecke, \& Krause, 2005). Non verbally, facial-affective behavior involves a specific desire of regulation, and conveys certain attitudes towards the interactive partner or towards the state of the relationship, including expectations about the interaction, which entail a specific relational offer to the interactive partner (Anstadt, Merten, Ullrich, \& Krause, 1997; Benecke, \& Krause, 2005; Merten, 1997; Rasting, \& Beutel, 2005). Specifically, Bänninger-Huber (1992) has observed that if the patient's relationship offer to the therapist, inviting her to play a particular role in the patient's relational scheme, is accepted, it involves the patient's repetition of dysfunctional patterns of negotiating interpersonal relationships. Non-verbal relational offers include the use of smiles as attempts to regulate an intra-psychic or relational disturbance evoked by negative emotions, seeking to establish a state of affective resonance with the therapist. Meanwhile, verbal offers include the expectation that the therapist act as an authority commenting on the patient's conflict, and therefore mitigate the patient's emotional disturbance associated to feelings of guilt (Bänninger-Huber, 1992; Bänninger-Huber, \& Widmer, 1999).

In this same line, other studies have observed that synchronous smile is a frequent pattern in almost all therapy sessions (Bänninger-Huber, 1992; Benecke, Peham, \& Bänninger-Huber, 2005; Merten, 2005; Rasting, \& Beutel, 2005) and it seems to serve the function of assuring a good therapeutic relationship and the probability of reciprocity. However, when it exceeds a certain threshold, it can serve as a defensive mechanism, by denying negative affects and avoiding conflict, thus establishing a maladaptive relational pattern in which the therapist enacts the patient's expectations and therapeutic work is hampered (Anstadt et al., 1997; Bänninger-Huber \& Widmer, 1999; Benecke \& Krause, 2005; Benecke et al., 2005; Dreher, Mengele, Krause, \& Kämmerer, 2001; Krause, \& Merten, 1999; Merten, 2005). 
Pág 183

A systematization and characterization of facial-verbal patterns of affect regulation between patient and therapist during ruptures and resolution strategies may contribute with markers that can allow a more attentive therapeutic work in the here and now of the interaction, and, in Safran's (2003) words, "aid clinicians in the development of pattern-recognition abilities that can facilitate the intervention process" (p. 461).
As the prior evidence indicates, the study of facial-affective behavior of patient and therapist, which is spontaneous and unconscious (Merten, 2005), allows an empirical access to processes that belong to the implicit domain of affective experience, that are involved in the regulation of the therapeutic relationship (Bänninger-Huber \& Widmer, 1999). It becomes therefore relevant to further examine how these facial-affective processes take place during ruptures, insofar as they constitute highly emotional relational contexts for both patient and therapist that challenge the stability of the relationship and the quality and progress of psychotherapy (Coutinho et al., 2011; Coutinho et al., 2014). In an attempt to examine this relationship Barros, Altimir and Pérez (2016) observed that during confrontation ruptures, where patients verbally challenged the therapist, their facial-affective behavior showed, emotional neutrality, thus favoring their sense of agency over their need for affiliation. This was interpreted as a defensive maneuver by the patients, which contributed to hide the intensity of their emotional dysregulation triggered by the rupture. Meanwhile, during withdrawal ruptures, a higher proportion of positive emotions were observed in patients, reflecting attempts to ensure a secure bond with the therapist in the face of relational conflict. This was interpreted as a tendency of patients to privilege the relationship over their sense of agency.

The previous findings underscore the value of combining both approaches for the study of the therapeutic relationship, as they allow an empirical access to the unconscious affective-regulatory processes between patient and therapist -expressed through verbal and nonverbal relational offers-, (Anstadt et al., 1997; Krause \& Merten, 1999), involved in ruptures. Furthermore, it can also allow a description of participants' facial-affective regulation displays during events where therapists make reparatory attempts -resolution strategies- for stabilizing ruptures, accounting for the counterpart in the process of relationship negotiation. A systematization and characterization of facial-verbal patterns of affect regulation between patient and therapist during ruptures and resolution strategies may contribute with markers that can allow a more attentive therapeutic work in the here and now of the interaction, and, in Safran's (2003) words, "aid clinicians in the development of pattern-recognition abilities that can facilitate the intervention process" (p. 461). This can help clinicians develop a greater sensitivity towards subtle but highly relevant interactive states that can translate into timely and contingent interventions and help ensure better psychotherapeutic treatments (Safran, 2003).

Therefore, the present study proposes to study the relationship between facial-affective behavior, verbal relational offers and rupture and resolution strategy events in a case of a brief psychodynamic therapy. The reason why this type of therapy was chosen is based on the shared theoretical background between the therapeutic approach of the case and the research approaches to psychotherapy process set out above, that is, a relational view of psychotherapy. Both share the assumption that the therapeutic relationship is the primary means by which the therapeutic process takes place and therefore change is possible. In Rozmarin and colleagues' words, "Both the practice and study of psychotherapy are, in this view, about understanding the vicissitudes of this relationship as it develops, affects participants, and reflects who they are" (Rozmarin et al., 2008, pp. 316). In that sense, they emphasize the underlying notion that all interventions, in addition to the explicit value in terms of information they contain, must also be understood as relational acts (Aron, 1996; Mitchell, 1988). 
Pág 184

The design of this research corresponds to a systematic case study, as it involves repeated systematic observation and measurement of behaviors deemed relevant to the therapeutic process -i.e., the therapeutic relationship-, in an attempt to establish associations between specific interventions and other variables of interest (Fonagy, \& Moran, 1993; Kächele, 2020).
The study seeks to answer the following questions: a) what characterizes the patient's and therapist's facial-affective behavior during rupture and resolution strategy events in a brief psychodynamic therapy? and b) how are their facial-affective behaviors associated with their verbal relational offers within these events? The hypotheses guiding this study are: (a) ruptures will be characterized by patient's facial display of negative emotions and indicators of emotional dysregulation, and (b) by therapist's indicators of emotional dysregulation, but maintained involvement towards the patient; (c) resolution strategies will be characterized by therapist's display of positive affect (smile) as a means of preserving the therapeutic relationship.

\section{Method}

\section{Design}

The design of this research corresponds to a systematic case study, as it involves repeated systematic observation and measurement of behaviors deemed relevant to the therapeutic process -i.e., the therapeutic relationship-, in an attempt to establish associations between specific interventions and other variables of interest (Fonagy, \& Moran, 1993; Kächele, 2020). In this study, systematic observation of repeated occurring events -ruptures and resolution strategies-, will be associated to verbal relational offers and nonverbal facial affective behavior. The value of this approach to the purpose of the study is that it allows an in-depth analysis of the moment-to-moment processes involved in the negotiation of the therapeutic relationship, considering the case-specific particularities and contexts of the therapeutic process (Kächele, 2020). At the same time, findings allow to extract hypotheses for future studies, contributing to the building of a cumulative database of cases, based upon which ultimately, general principles of psychotherapeutic work and intervention may be drawn (Altimir, \& Jiménez, 2020).

\section{Participants}

The participants of this study were a patient and therapist of a brief psychodynamic therapy that was carried out once a week in a specialized center for focal psychodynamic therapy training. The therapist was a 53-year-old male, trained psychoanalyst, and faculty member of this center, with over 20 years of clinical experience. The patient was a 33-year-old single female who sought help for mild depressive symptoms and interpersonal issues with family and romantic partners. She was referred to the center several months after ending a previous treatment that lasted approximately one year, since she could not keep affording a private psychotherapy. The therapy lasted 31 session, but 30 sessions were available for analyses ${ }^{1}$. The selection of this psychotherapy responded to the availability of the center, as well as of the participants, to allow access to the entire psychotherapeutic process for research purposes.

\section{Sample}

The sample was composed of 36 events -22 ruptures and 14 resolution strategies-, identified by two trained judges along the 30 videotaped therapy sessions, based on an observational rating system (see measures section). Coders observed each therapy session and identified markers of both ruptures and resolution strategies according to the definition of the manual. Confrontation and withdrawal ruptures were homogeneously distributed (11 each). Not all therapy sessions contained rupture or resolution strategy episodes; therefore, the average of overall episodes per session was of 0.8 .

1. The patient asked that session four was not videotaped nor observed by the psychotherapy trainees. 


\section{Measures}

Outcome measures

Outcome measures were applied as a means of having a parameter of the patient's overall process of change and the general characteristics of the psychotherapeutic process. In this way, the overall measures of outcome can provide a basis to interpret and provide a context to the process variables involved in the examination of the therapeutic relationship.

The Chilean version of the Outcome Questionnaire (OQ-45.2) (de la Parra, von Bergen, \& del Rio, 2002) was used to assess therapeutic outcome based on the patient's level of functioning along the dimensions of Subjective Discomfort, Interpersonal Relations and Social Role. It defines a cut-off score to differentiate functional and non-functional population and a Reliable Change Index to evaluate clinically significant change, based on a pre-post estimation. The instrument has shown an adequate degree of reliability (Cronbach Alpha of .91).

The Hierarchy of Generic Change Indicators (GCls) (Krause et al., 2007) is a system for the observational coding of patient's change referred to the subjective patterns of interpretation and explanation regarding his/herself, his/her problems and personal surroundings. This model assumes a progression of change towards higher levels of elaboration of the explanatory patterns and meaning-making process of the patient along three main stages (Altimir et al., 2010): (I) initial consolidation of the structure of the therapeutic relationship (i.e., patient's acceptance of his/her own limits and the need for help, acceptance of the therapist as a competent professional, questioning of usual ways of understanding); (II) increase in the permeability towards new understandings (i.e., discovery of new aspects of self, manifestation of new behaviors or emotions, reconceptualization of problems and/or symptoms); and (III) construction and consolidation of a new understanding (i.e., the development of subjective constructs of self, their founding in the patient's own biography, and a decreased asymmetry between patient and therapist). Judges observe therapy sessions and code the presence of $\mathrm{GCl}$. Previous studies support the positive association between higher stage indicators and outcome (Krause, Altimir, Pérez, \& de la Parra, 2014).

\section{Process measures}

The Rupture and Resolution Rating System (3RS) (Eubanks, Muran, \& Safran, 2015), is a system that allows the observational coding of rupture and resolution strategy markers by judges. While observing the session, judges record events in which a lack of collaboration and/or tension between patient and therapist is observed, as well as events in which the therapist attempts a resolution strategy.

The Facial Action Coding System (FACS) (Ekman and Friesen, 1978), is an observational system that allows the objective coding of facial behavior. Distinct combinations of facial movements are associated to the presence of basic emotions (happiness, anger, contempt, disgust, fear, sadness and surprise), as well as social smile (directed at resonating with the interactive partner). The system also allows coding of behavioral indicators of emotional arousal and attempts at regulation including gaze behavior (regulates emotional involvement in the interaction and direction of the expressed affect) (Anstadt et al., 1997), self-touching (adaptors) (indicators of emotional tension or arousal and the attempt at self-regulation), control/attenuation of facial expressions (movements around the mouth that indicate self-regulation of the expression) (Ekman 
Pág 186

For the assessment of the patient's transformation of subjective patterns of interpretation and explanation by means of the Generic Change Indicators (GCls), two trained judges (both psychologists, including the first author) independently rated all therapy sessions.
\& Friesen, 1982), and elevation of the eyebrows (illustrators) (serve the function of emphasizing what is being expressed or perceived through other communication channels or of conveying a question mark) (Ekman, 1979).

\section{Procedure}

Therapist and patient were recruited through the leading author's contact with the psychotherapy training center. Therapy took place in a therapeutic training context and involved its observation through a one-way mirror by a group of therapy trainees and supervisors. Patient and therapist signed a written consent accepting to participate from this study. All psychotherapeutic sessions were video-taped by means of two separate cameras that provided a frontal view of each participant's face. Patient completed the Outcome Questionnaire before every session from intake to termination, although only the intake and final scores were used to estimate reliable clinical change.

For the assessment of the patient's transformation of subjective patterns of interpretation and explanation by means of the Generic Change Indicators (GCls), two trained judges (both psychologists, including the first author) independently rated all therapy sessions. An inter-rater reliability estimate of these ratings yielded a Kappa coefficient of .51 ( $\mathrm{p} \leq .001,95 \% \mathrm{Cl} 0.35-0.66$ ) on $80 \%$ of therapy sessions. Regardless of this, raters arrived at an intersubjective consensus on the presence and content of the GCls. Only GCls that were agreed upon were considered for the assessment of change on this dimension.

Analyses of the process variables were conducted at three times during the research. First, a second pair of trained judges (both psychologists, also including the first author), coded the presence of rupture and resolution strategy events. Inter-rater reliability was estimated based on each raters' separate coding, showing a good level of agreement on the presence of ruptures $(\mathrm{K}=.64, p<.000,95 \% \mathrm{Cl} 0.5078-0.7722)$, and resolution strategies ( $\mathrm{K}=.72, p<.000,95 \% \mathrm{Cl} 0.5985-0.8469)$ (Fleiss, Levin, \& Cho Paik, 1981). Definitive presence of the events was determined through intersubjective consensus, leaving out of the analysis those that did not reach agreement.

Second, patient's and therapist's verbal relational offers within each rupture and resolution strategy event previously identified were determined by the two authors through a Qualitative Content Analysis of both participant's verbal communication, being blind to the type of event, and triangulating their coding to achieve an intersubjective agreement. Relational offers were defined as units of meaning within verbal utterances where the speaker implicitly and/or explicitly assumes a position that determines how he/she experiences him/herself in relation to the interactive partner, as well as how he/she experiences the interactive partner, and therefore the complementary position or role she expects him/her to adopt in response. These units of meaning may include an entire speaking turn or portions of it. According to the position assumed by the speaker and the relational expectation associated to each unit of meaning, raters labeled each relational offer with an allusive name (i.e., when the patient expressed a position of emotional connection with herself, offering the therapist a complementary role of containment and understanding, the relational offer made by the patient was labeled "fragile"). 
A database was created where each rupture and resolution strategy event were associated to the corresponding verbal relational offers coded within them, as well as with patients and therapists' facial affective behavior. Patient's and therapist's facial behavior within ROs and rupture and resolution strategy events were modeled by means of nested hierarchical regressions using Hierarchical Linear Modeling (HLM).
The third step was to determine the patient's and therapist's facial-affective behavior within rupture and resolution strategy events. This procedure was carried out by the leading author, certified in the use of FACS, for the totality of the events. Since facial movements occur very rapidly, they were coded at a micro-level (Bänninger-Huber, 1992), implying that rupture and resolution strategy events were divided into video-frames of .04 seconds resolution, yielding a total of 3502 video-frames (1751 for each participant's facial behavior). In order to assure reliability on the FACs coding, inter-rater agreement between the primary coder and a second coder (also trained and certified in FACS), was estimated on $31 \%$ of the total sample of micro-behavior video-frames, based on a random selection of the events. Good level of agreement was found on the presence of facial events $(\mathrm{K}=.61, \mathrm{Cl} 0.5564-0.657, p<.000)$, as well as on the emotions of disgust $(\mathrm{K}=.64, \mathrm{Cl} 0.4153-0.8615, p<.000)$, fear $(\mathrm{K}=.71, \mathrm{Cl} 0.6142-0.7978, p<.000)$, and happiness $(\mathrm{K}=.62, \mathrm{Cl} 0.5271-0.7165, p<.000)$. Excellent level of agreement was estimated on gaze behavior ( $\mathrm{K}=.78, \mathrm{Cl} 0.7373-0.8167, p<.000$ ) and self-soothing behavior (face and body adaptors) ( $\mathrm{K}=.93, \mathrm{Cl} 0.906-0.957, p<.000$ ). Finally, moderate levels of agreement were found for positive affect $(K=.50, \mathrm{Cl} 0.3828-0.6182)$ and illustrators $(\mathrm{K}=.55, \mathrm{Cl}$ 0.4775-0.6255, $p<.000)$ (Sayette, Cohn, Wertz, Perrott, \& Parrott, 2001).

A database was created where each rupture and resolution strategy event were associated to the corresponding verbal relational offers RO coded within them, as well as with patients and therapists' facial affective behavior. Patient's and therapist's facial behavior within ROs and rupture and resolution strategy events were modeled by means of nested hierarchical regressions using Hierarchical Linear Modeling (HLM). A three-level model was estimated, where participants' facial behavior was defined as the dependent variable and RO and type of event as the predictor variables. Level-1 was defined as participants' facial behavior at the video-frame level ( $N=$ 1751), Level-2 was established at the utterance level defined by each RO ( $N=164)$, and Level-3 was established at the event level defined by the presence of ruptures or resolution strategies. All variables were dichotomized using the Bernoulli model (Raudenbush, Bryk, Cheong, Congdon, \& du Toit, 2004). Separate nested models were estimated for the probability of occurrence of each Level-1 dependent variable, which was centered with respect to the mean of each event level. Only the models that converged are reported in these results.

\section{Results}

\section{Patient's overall change}

The initial and final OQ-45.2 scores indicate that the patient did not achieve a clinically significant change according to the reliable change index. However, she remained within the functional population, thus showing a functional level of well-being throughout the process (Lambert et al. 1996). Meanwhile, the frequency of patient's in-session GCls show that from a total of $46 \mathrm{GCls}$ identified, $17.4 \%$ belonged to Stage I, $67.4 \%$ to Stage II, and $15.2 \%$ to Stage III. Analysis of the difference between proportions indicate that the predominance of Stage II GCls was statistically significant compared to Stage I $(Z=-4.852$, IC 0.3036-0.6438, $p<.0001)$ and to Stage III ( $Z$ $=5.082$, IC $0.3275-0.6619, p<.0001)$ GCls. These results indicate that the patient achieved a mid-level transformation of her subjective theories regarding herself, her problems and her surroundings.

\section{Ruptures and Resolution Strategies}

Observational coding of the 30 therapy sessions yielded 36 events: 22 rupture (R) events -11 confrontations and 11 withdrawals-, and 14 resolution strategies (RS). 


\section{Participants' Verbal Relational Offers}

Content analysis of the participants' verbal utterances within the 36 rupture and resolutions strategy events yielded a total of 164 units of meaning. Each unit of meaning was then categorized into four relational offers (RO) enunciated by the patient and four enunciated by the therapist. Table 1 shows each RO indicating the position adopted by the speaker, the complementary position the interactive partner is implicitly or explicitly expected to adopt, and an illustrating vignette.

Table 1. Patient's and therapist's verbal relational offers

\section{Patient's Relational Offers}

\begin{tabular}{|c|c|c|c|}
\hline & Position of self & Expected position of other & Vignette \\
\hline Stoic & $\begin{array}{l}\text { Must deal with and } \\
\text { bear adverse external } \\
\text { circumstances or own } \\
\text { difficulties in a self- } \\
\text { sufficient way }\end{array}$ & $\begin{array}{l}\text { Accepts patient's stance } \\
\text { and does not offer help, } \\
\text { withdraws and justifies } \\
\text { patient's stoicism without } \\
\text { question or judgement }\end{array}$ & $\begin{array}{l}\text { What I have to learn is how to } \\
\text { manage it, how to endure it and } \\
\text { to overcome it some other way } \\
\text { [...] life sends you things that you } \\
\text { can cope with, things that make } \\
\text { you stand up as a person }\end{array}$ \\
\hline Fragile & $\begin{array}{l}\text { Connected with own } \\
\text { needs, recognizes own } \\
\text { vulnerabilities but } \\
\text { experiences them as } \\
\text { weakness. }\end{array}$ & $\begin{array}{l}\text { Helps and supports } \\
\text { patient, is empathetic but } \\
\text { must be sensitive to the } \\
\text { other's sense of fragility }\end{array}$ & $\begin{array}{l}\text { I'm trying to take the positive } \\
\text { side of this. But evidently, yes! } \\
\text { At times I do feel overwhelmed, } \\
\text { but that is why I'm here, to try to } \\
\text { understand and help myself }\end{array}$ \\
\hline Defensive & $\begin{array}{l}\text { Determined and } \\
\text { reluctant to new } \\
\text { possibilities, acts } \\
\text { rejectingly or } \\
\text { closes up through } \\
\text { indifference. }\end{array}$ & $\begin{array}{l}\text { Refrains from intervening } \\
\text { or offering new meanings } \\
\text { or perspectives, keeps } \\
\text { emotional distance and } \\
\text { remains at surface level. }\end{array}$ & $\begin{array}{l}\text {...I'm not interested in becoming } \\
\text { sad or in judging my parents } \\
\text { more than what I have already } \\
\text { judged them. I don't want to dwell } \\
\text { on the anger that at some point I } \\
\text { felt towards them }\end{array}$ \\
\hline Receptive & $\begin{array}{l}\text { Open to exploring new } \\
\text { or deeper meanings or } \\
\text { experiences without } \\
\text { feeling threatened. }\end{array}$ & $\begin{array}{l}\text { Actively offers } \\
\text { associations, new } \\
\text { perspectives, and } \\
\text { guidance. }\end{array}$ & $\begin{array}{l}\text { Yes, it may be, but it was not } \\
\text { my intention [...] yes, I may have } \\
\text { perceived it, but if I did, it was } \\
\text { unintentionally }\end{array}$ \\
\hline \multicolumn{4}{|c|}{ Therapist's Relational Offers } \\
\hline & Position of self & Expected position of other & \\
\hline Questioning & $\begin{array}{l}\text { Inquires and invites } \\
\text { to make new } \\
\text { associations, or } \\
\text { confronts, keeping a } \\
\text { friendly attitude }\end{array}$ & $\begin{array}{l}\text { Opens to accept new } \\
\text { formulations and to be } \\
\text { questioned and influenced. }\end{array}$ & $\begin{array}{l}\text { Of course! The point is that you } \\
\text { do not ask for it (a lowering of the } \\
\text { session fee). That's the point }\end{array}$ \\
\hline Propositive & $\begin{array}{l}\text { An expert who } \\
\text { proposes, explains } \\
\text { and offers new } \\
\text { formulations from } \\
\text { the position of a } \\
\text { benevolent authority. }\end{array}$ & $\begin{array}{l}\text { Adopts a cognitively willing } \\
\text { and open position, allows } \\
\text { to be taught and guided. }\end{array}$ & $\begin{array}{l}\text { For example, right now when I'm } \\
\text { telling you this I can sense, I'm } \\
\text { not sure if you agree with me, but } \\
\text { I sense that you feel evaluated as } \\
\text { to whether what we are talking } \\
\text { about is good or bad }\end{array}$ \\
\hline Conciliator & $\begin{array}{l}\text { Understanding, } \\
\text { empathetic, caring, } \\
\text { soothing, and } \\
\text { understanding }\end{array}$ & $\begin{array}{l}\text { Connects with difficult } \\
\text { emotions, feels } \\
\text { acknowledged and } \\
\text { understood. }\end{array}$ & $\begin{array}{l}\text { I kept thinking that you may have } \\
\text { felt that as a criticism and not as } \\
\text { something I could have said to } \\
\text { you because we are both going to } \\
\text { separate }\end{array}$ \\
\hline Exploring & $\begin{array}{l}\text { Genuinely interested } \\
\text { in understanding the } \\
\text { patient's experience, is } \\
\text { curious but cautious. }\end{array}$ & $\begin{array}{l}\text { Trusts and is willing to } \\
\text { explore inner world and } \\
\text { experiences. }\end{array}$ & $\begin{array}{l}\text { May it be further on (the date of } \\
\text { therapy termination)? But you } \\
\text { may think about it, how you feel } \\
\text { about it [...] let's think about it } \\
\text { then }\end{array}$ \\
\hline
\end{tabular}


When analyzing therapist's facial behavior, results indicated that there was a greater probability of therapist gazing at patient, as well as displaying self-soothing and control regulatory behaviors during rupture events.
When comparing each participant's verbal ROs, according to the type of event (rupture or resolution strategy events), results show that patient's RO Receptive was significantly more frequent during resolution strategies $(Z=-3.802, p<.0002, \mathrm{Cl} 95 \%$ $0.1807-0.6673)$, as did therapist's RO Propositive $(Z=-3.959, p<.0002, \mathrm{Cl} 95 \% 0.228$ - 0.5999), whereas therapist's RO Questioning was significantly more frequent during rupture events $(Z=3.198, p=.0004, \mathrm{Cl} 95 \% 0.1199-0.49)$.

In order to assess changes in the participants' ROs throughout the therapeutic process, therapy was divided into three phases. Results show that the patient's RO Fragile was significantly more frequent during the final phase of therapy, compared to the initial and middle phases ( $p<.05, \mathrm{Cl} 95 \%$ 0.0144-0.3318; $p<.05, \mathrm{Cl} 95 \% 0.0437-$ 0.3618); whereas the therapist's RO Explorer was significantly more frequent during the middle phase of therapy, compared to the initial phase ( $p<.05, \mathrm{Cl} 95 \% 0.0112-$ 0.2092), while it was not present during the final phase of therapy. (For both analyses, the $Z$ coefficient was not calculated since the criteria $n(p)$ and $n(1-p)$ equal or greater than 5 was not met).

\section{Participants' Facial Affective Behavior}

Patient's and therapist's facial behavior within ROs and rupture and resolution strategy events were modeled by means of nested hierarchical regressions using HLM. The present study reports only the models that converged in the estimation of the three-level model by means of HLM, where participants' facial behavior was defined as the dependent variable and RO and type of event as the predictor variables.

Patient's facial-affective behavior within RO and rupture-resolution strategy events Results of the HLM fixed effects modeling indicated that the patient has more probability of displaying anger during rupture events (OR $=.29, p<.05)$, without ROs explaining any variability of this emotion. Within these same events, patient is more likely to display fear $(\mathrm{OR}=.00, \mathrm{p}<.01)$ and indicators of control of facial expression (regulatory behavior) (OR $=.22, p<.05)$ while therapist enunciates RO Propositive. Also, within rupture events, the patient showed higher probabilities of gazing away from the therapist while enunciating RO Receptive $(\mathrm{OR}=.04, \mathrm{p}<.01)$; and displaying self-soothing behavior while therapist enunciated ROs Questioning (OR $=.02, p<.05)$ and Conciliator (OR $=.03, p<.05)$. Regardless of the type of event, a positive association between patient gazing at therapist and therapist's RO Propositive was observed $(\mathrm{OR}=4.08, \mathrm{p}<.01)$. Meanwhile, patient's' facial-affective behavior during resolution strategy events indicates a consistent likelihood of patient gazing at therapist $(\mathrm{OR}=$ $8.9, p<.001 ; O R=8.46, p<.001 ; O R=10.08, p<.001 ; O R=8.52, p<.001 ; O R=9.79, p$ $<.001$ ), and of displaying self-soothing behavior (OR = 4.91, $p<.05 ; \mathrm{OR}=7.57, \mathrm{p}<.01$; $\mathrm{OR}=6.52, \mathrm{p}<.05)$, with no RO Level-2 variables explaining this association. Patient's display of happiness, social smiles, and illustrators (facial indicators of emphasis or interrogation) is not explained by any of the fixed models estimated (see Appendix $A$ and $B)$.

Therapist's facial-affective behavior, within RO and rupture-resolution strategy events When analyzing therapist's facial behavior, results indicated that there was a greater probability of therapist gazing at patient, as well as displaying self-soothing and control regulatory behaviors during rupture events. Predictors at Level-2 (ROs) did not explain this variability. Meanwhile, during resolution strategy events, therapist showed less probability of displaying happiness (and therefore positive affect) while enunciating RO Propositive (OR $=8.69, \mathrm{p}<.05)$. The variability of therapist's expression of sadness, and social smile are not explained by the fixed models carried out. Irrespective of Level-2 
Pág 190

Results indicate that no clinically significant change was observed in the first dimension, although the patient remained in a functional level throughout the therapeutic process. This may be due to her low level of distress at session intake, suggesting a possible influence of the patient's previous treatment not long before initiating the actual therapy on her symptom remission. However, regarding the dimension of transformations of subjective explanations, results show that the patient achieved an increase in permeability towards new understandings and meanings (Stage II GCls). predictors (ROs), therapist was also more likely to display illustrators (emphasis or interrogation) during resolution strategies $(R O=3.51, p<.05 ; R O=3.87, p<.01 ; R 0$ $=3.24, p<.05 ; R 0=3.32, p<.05)$. Meanwhile, irrespective of the type of event within which the interaction is taking place, therapist's RO Questioning shows a negative association to self-soothing $(\mathrm{OR}=.07, \mathrm{p}<.01)$ and control regulatory behaviors (OR $=.18, p<.05)$, and a positive association to illustrators (OR $=4.76, p<.05)$ (see Appendix C and D).

\section{Discussion}

The present study is intended to contribute to a deeper understanding of how the therapeutic relationship is negotiated, by examining the association between participants' facial-affective behavior, verbal relational offers, and rupture and resolution strategy events, in a case of a brief psychodynamic therapy. Outcome measures assessing the patient's degree of change were included as a means of having a global perspective on the characteristics of the psychotherapeutic process. The information on these overall measures of outcome was intended to provide a contextual framework within which the analyses of the therapeutic process variables can acquire meaning. Thus, patient's change was assessed at two levels: (a) symptomatic and psychological distress, and (b) representational change and transformation of explanatory theories.

Results indicate that no clinically significant change was observed in the first dimension, although the patient remained in a functional level throughout the therapeutic process. This may be due to her low level of distress at session intake, suggesting a possible influence of the patient's previous treatment not long before initiating the actual therapy on her symptom remission. However, regarding the dimension of transformations of subjective explanations, results show that the patient achieved an increase in permeability towards new understandings and meanings (Stage II GCls). As a previous study by Krause et al. (2014) suggests, patients that do not achieve a clinically significant change measured by the OQ-45.2 may require longer therapies to consolidate Stage III GCls. Thus, these overall measures indicate that the patient achieved changes as a consequence of the psychotherapeutic process, although she did not evidence a full range level of achievement. This result can be interpreted as concordant with the characteristics of a focal psychotherapy, where some identified elements of her psychological conflicts -i.e., interpersonal issues with family and romantic partners, and depressive symptoms-, were particularly addressed, at the expense of others.

The examination of the different process variables indicated that rupture events almost doubled resolution strategy events within the therapeutic process. This result is not surprising, considering what Eubanks et al (2015) point out as a common feature of ruptures: they may remain outside the patient and therapist's conscious awareness, and on occasions may not significantly obstruct therapeutic progress.

When analyzing the frequency and distribution of participants' RO throughout the psychotherapeutic process, results indicate an increase in patient's RO Fragile towards the final phase of therapy. This may be considered as a third dimension of therapeutic change, namely, that of the patients' relational repertoires set forward as a consequence of the establishment and consolidation of the therapeutic relationship. In this case, patient shows a progressive adoption of a position in which she connects with her own needs and recognizes her vulnerability, inviting the therapist to adopt a supportive and sensitive stance towards her. This dimension of the patient's change supports the underlying assumption of psychodynamic approaches, 
Regarding patient's facial behavior during ruptures, results confirm our first hypothesis of patient's greater display of negative emotions and indicators of emotional dysregulation during these events. Within a relational context in which the relationship is temporarily at stake, the patient displays anger at the nonverbal level. Anger within the therapeutic interaction has been described to reactivate internal conflicts related with these emotions in the patient, thus triggering affective dysregulation (Merten, 1997). including that of the present case, that the therapeutic relationship is the primary means by which therapeutic change is possible. It can be argued that as a consequence of the patient establishing a particular kind of relationship with the therapist, within which her needs were negotiated and explored, she was progressively able to acknowledge them and reorganize her relational repertoires to include her fragility in the face of interpersonal relationships.

The distribution of ROs along rupture and resolution strategy events indicates a predominance of therapist Questioning during ruptures, which is coherent with the inherent confrontation and inquiry of this offer. It can be argued that this offer may play a part in the configuration of the rupture event, as patient may react negatively to what she may experience as a judgmental or critical position of the therapist. Meanwhile, a predominance of therapist's RO Propositive during resolution strategies may indicate a relational interaction that is attuned with the therapist's repairing attempts, as he adopts a friendlier and less threatening invitation to the patient to adopt an introspective position regarding previous ruptures. By the same token, patient's more frequent RO Receptive during resolution strategies may be understood as a complementary position that is open to the reparatory attempt. Given the characteristic relational movements implied in ruptures and resolution strategies, it can be expected that the predominant ROs proposed by each participant show a content that is isomorphic to the relational context in which it takes place.

The nested analyses of participants' facial behavior within specific ROs and types of events, yielded results that support the assumption that rupture and resolution strategy events constitute relational and interactive contexts that involve specific regulatory processes both at the verbal as well as facial-affective level of communication.

Regarding patient's facial behavior during ruptures, results confirm our first hypothesis of patient's greater display of negative emotions and indicators of emotional dysregulation during these events. Within a relational context in which the relationship is temporarily at stake, the patient displays anger at the nonverbal level. Anger within the therapeutic interaction has been described to reactivate internal conflicts related with these emotions in the patient, thus triggering affective dysregulation (Merten, 1997). It has also been considered a sign of blocked goals and a subsequent lack of compliance with the therapist's purposes (Merten, 2005). Thus, the function of anger within rupture events can be understood in either sense. Nevertheless, patient's emotional display is also conditioned by the therapist's as well as her own ROs. Patient has shown to display fear and control processes when therapist offers new formulations with a warm, careful and empathetic attitude, inviting the patient to adopt an introspective stance (RO Propositive), within ruptures. From an interactive regulatory perspective, this can be interpreted as patient facially expressing her difficulties in accepting this invitation in the context of a relational impasse, where she may feel more threatened to get in touch with her inner experience or vulnerability.

Meanwhile, patient's display of self-soothing behavior during ruptures, when the therapist verbally challenges and confronts her through questioning, or when he invites her to be contained and supported by the therapist in a conciliating way, indicates her emotional dysregulation and disturbance. These two ROs by the therapist can be considered as relationship negotiation maneuvers which are particularly disruptive for the patient, as they offer her a position in the line of dependency: to accept being influenced or to accept being guided towards introspection and emotional connection. A 
Pág 192

Our third hypothesis establishing the presence of therapist's positive affect and smiling behavior during resolution strategies, as a means of preserving the therapeutic relationship, was not confirmed. Instead, our results show that during resolution strategies, when the therapist provides relational offers (RO) Propositive, where he adopts an expert position and offers new formulation from a position of authority, nonverbally he is less likely to express positive emotions. different scene is observed when the patient is the one to offer a position in which she is willing to explore and deepen contents and expects the therapist to offer guidance, in the midst of a rupture. Here, while the patient seems to connect with her needs for dependency, emotional arousal is unbearable and therefore she avoids emotional involvement with the therapist by gazing away, thus contributing to shaping the rupture events.

As a different interactive scenario, where attempts at exploring patient's inner experience are made, resolution strategies are characterized by patient's emotional involvement through gazing at the therapist, at the same time that she displays self-soothing (self-regulating) strategies to deal with emotional arousal. If we consider that resolution strategies are laborious attempts at recognition of difficult underlying emotions and self-states triggered by ruptures, it makes sense that such a connection be emotionally stressful for the patient. Finally, patient's disposition to involve with the therapist through gazing as he proposes interventions and new perspectives is evidenced during RO Propositive, irrespective of the type of event, perhaps as an acceptance of therapist's friendly and caring approach.

Findings regarding therapist's facial-affective behavior support our second hypothesis that ruptures will be characterized by therapist's display of emotional dysregulation indicators -in this case self-soothing and control- but maintained gaze towards patient. This was irrespective of the participants' ROs. Given the challenge that ruptures imply for the stability of the relationship, therapist's gazing at the patient within these events can be interpreted as his emotional involvement and acknowledgment of their relevance for the therapy. Clinically, this behavior would be expected from an experienced therapist that is used to these setbacks during the therapeutic process and is actively interested in seizing them as opportunities for therapeutic work. At the same time, the intensity of the situation may imply a concomitant emotional dysregulation in the therapist, which he addresses through self-soothing behaviors. At the same time, by controlling his facial reactions he might be attempting to attenuate the intensity of the emotions expressed during this relational conflict.

On the other hand, when the interaction takes place within a resolution strategy, irrespective of the relational offers being proposed by the participants, therapist shows a predominance of illustrators (simultaneous lifting of inner and outer eyebrows), which based on the literature on emotions (Ekman, 1979), can in this case be considered as indicators of an emphasis on what the therapist is expressing, insofar as he may be interested in drawing the patient's attention to the process of addressing a previous rupture. Furthermore, in the cases in which the resolution strategy conveyed by the therapist adopts the form of an inquiry and invitation to the patient to explore her feelings regarding the rupture, these illustrators may have the specific function of conveying a question mark.

However, our third hypothesis establishing the presence of therapist's positive affect and smiling behavior during resolution strategies, as a means of preserving the therapeutic relationship, was not confirmed. Instead, our results show that during resolution strategies, when the therapist provides RO Propositive, where he adopts an expert position and offers new formulation from a position of authority, nonverbally he is less likely to express positive emotions. Perhaps during these relational scenarios, the therapist is not so worried about resonating with the patient through smiling, but instead seeks to convey the relevance of his propositions and the interest in the therapeutic work of repairing. This may respond to what Bänninger-Huber 
The research approach offered by the systematic single case study design has evidenced the possibility of establishing synchronic associations between different levels of analysis, as well as between the verbal and nonverbal dimensions of the therapeutic experience, inasmuch the relevant patterns observed at the split-second level of facial expression are consistent with the contents of the relational offers at the speech turn, and the interactive context of the ruptures and resolution strategies.
(1992; Bänninger-Huber, \& Widmer, 1999) has observed in previous studies, that an excessive use of smiles by the therapist can serve a function of denying negative affect and avoiding conflict. It seems that during these events, the therapist is instead interested in addressing the previous conflict. This interpretation is supported by the therapist's display of illustrators -as a means of emphasizing an intervention or interrogating the patient-, during resolution strategies. Finally, therapist's predominant display of illustrators, as well as less likelihood of displaying control processes during RO Questioning, irrespective of the type of event, is coherent with the position this offer conveys of interrogating and inviting to associate and connect in a friendly way. It seems this position triggers little emotional dysregulation on the therapist as well.

The results from this study contribute with insights into the nature of the affect regulation of patient and therapist within the therapeutic encounter. The research approach offered by the systematic single case study design has evidenced the possibility of establishing synchronic associations between different levels of analysis, as well as between the verbal and nonverbal dimensions of the therapeutic experience, inasmuch the relevant patterns observed at the split-second level of facial expression are consistent with the contents of the relational offers at the speech turn, and the interactive context of the ruptures and resolution strategies. Although we acknowledge that the present results are specific to a particular dyad and that other configurations of related behaviors can be found in different dyads, we nevertheless argue in favor of the richness and depth of analysis provided by the single case. We are also conscious that although the different interpretations given to the results found in this study may be plausible, further research along a cumulative number of cases is required, in order to draw recurring patterns of affect regulation between patient and therapist that are relevant to the therapeutic relationship as well as to the change process.

A further limitation of this study regards the small number of rupture and resolution strategy events, which was not enough to allow for a comparison between confrontation and withdrawal ruptures. This comparison would contribute with even more contextual information for interpreting facial behavior and possibly extracting differentiated patterns of behavior, associated to the verbal relational offers. Future research should contemplate the possibility of assuring a greater number of events, by including more therapies. This may also contribute to a greater variability of facial-affective behavior, specially of basic emotions, whose distribution did not allow examining other patterns of display. An additional limitation of this study relates to the possible associations between regulatory processes at the event level and therapy outcome and patient's change process. Given the single case design of this study, outcome measures were used as a contextual framework of how this particular patient progressed due to therapy. We expect that further research in verbal and facial-affective regulatory processes involved in the negotiation of the therapeutic relationship, may establish associations between these variables and process outcome indicators, which may contribute to develop guidelines for more effective clinical interventions. 


\section{References}

Altimir, C., \&. Jiménez, J.P. (2020). Walking the middle ground between hermeneutics and science: A research proposal on psychoanalytic process. The International Journal of Psychoanalysis, 101(3), 496-522 https://doi.org/10.1080/00207578.2 020.1726711

Altimir, C., Krause, M., de la Parra, G., Dagnino, P., Tomicic, A., Valdés, N.,... Vilches, O. (2010). Clients', therapists', and observers' agreement on the amount, temporal location, and content of psychotherapeutic change and its relation to outcome. Psychotherapy Research, 20, 4, 472 - 487. https://doi.org/10.1080/10503301003705871

Anstadt, T., Merten, J., Ullrich, B., \& Krause, R. (1997). Affective dyadic behavior, core conflictual relationship themes, and success of treatment. Psychotherapy Research, 7, 397-417. https://doi.org/10.1080/10503309712331332103

Aron, L. (1996). A meeting of minds: Mutuality in psychoanalysis. Hillsdale, NJ: Analytic Press.

Bänninger-Huber, E. (1992). Prototypical affective microsequences in psychotherapeutic interaction. Psychotherapy Research, 2, 291-306. https://doi.org/10.1080 110503309212331333044

Bänninger-Huber, E., \& Widmer, C. (1999). Affective relationship patterns and psychotherapeutic change. Psychotherapy Research, 9, 74-87. https://doi.org/10.10 $\underline{80 / 10503309912331332601}$

Barros, P., Altimir, C., \& Pérez, J.C. (2016). Patients' facial-affective regulation during episodes of rupture of the therapeutic alliance / Regulación afectivo-facial de pacientes durante episodios de ruptura de la alianza terapéutica. Estudios de Psicología, 37, 2-3, 580-603. https://doi.org/10.1080/02109395.2016.1204781

Benecke, C., \& Krause, R. (2005). Facial affective relationship offers of patients with panic disorder. Psychotherapy Research, 15, 178-187. https://doi.org/10.1080/1 0503300512331335048

Benecke, C., Peham, D., \& Bänninger-Huber, E. (2005). Nonverbal relationship regulation in psychotherapy. Psychotherapy Research, 15, 81-90. https://doi.org/10.10 80/10503300512331327065

Castonguay, L.G., Goldfried, M.R., Wiser, S., Raue, P.J., \& Hayes, A.M. (1996). Predicting the effect of cognitive therapy for depression: A study of unique and common factors. Journal of Consulting and Clinical Psychology, 64, 497-504. https://doi. org/10.1037/0022-006X.64.3.497

Coutinho, J., Ribeiro, E., Fernandes, C., Sousa, I., \& Safran, J. D. (2014). The development of the therapeutic alliance and the emergence of alliance ruptures. Anales de Psicología, 30(3), 985-994. http://dx.doi.org/10.6018/analesps.30.3.168911

Coutinho, J., Ribeiro, E., Hill, C., \& Safran, J. D. (2011). Therapists' and clients' experiences of alliance ruptures: A qualitative study. Psychotherapy Research, 21(5), 525-540. http://dx.doi.org/10.1080/10503307.2011.587469

de la Parra, G., von Bergen, A., \& del Río, M. (2002). Primeros hallazgos de la aplicación de un instrumento que mide resultados psicoterapéuticos en una muestra de pacientes y de población general. Revista Chilena de Neuropsiquiatría, 40, 201-209. http://dx.doi.org/10.4067/S0717-92272002000300003

Dreher, M., Mengele., U., Krause, R., \& Kämmerer, A. (2001). Affective indicators of the psychotherapeutic process: An empirical case study. Psychotherapy Research, 11, 99-117. https://doi.org/10.1080/713663855

Ekman, P. (1979). About brows: Emotional and conversational signals. In M von Cranach, K. Foppa, W. Lepenies and D. Ploog (Eds.) (pp. 169-249). Human Ethology. Cambridge, UK: Cambridge University Press. 
Ekman, P., \& Friesen, W. V. (1978). Facial action coding system: A technique for the measurement of facial movement. Palo Alto, California: Consulting Psychologists Press.

Ekman, P., \& Friesen, W. V. (1982). Felt, false, and miserable smiles. Journal of Nonverbal Behavior, 6(4), 238-252. https://doi.org/0191-5886/82/1400-0238

Eubanks, C. F., Muran, J. C., \& Safran, J. D. (2015). Rupture Resolution Rating System (3RS): Manual. Technical Report.

Fleiss, J. L., Levin, B., \& Cho Paik, M. (1981). Statistical Methods for Rates and Proportions. ( $3^{\text {rd }}$. ed). New York: John Wiley \& Sons.

Fonagy, P., \& G. Moran, (1993). Selecting Single Case Research Designs for Clinicians. In E. N. Miller, L. Luborsky, J. P. Barber, and J. P. Docherty (Eds.). Psychodynamic Treatment Research: A Handbook for Clinical Practice (pp. 62-95). New York: Basic Books.

Horvath, A. O., Del Re, A. C., Flückiger, C., \& Symonds, D. (2011). Alliance in individual psychotherapy. Psychotherapy, 48, 9-16. https://doi.org/10.1037/a0022186

Kächele, H. (2020). From case study to single case research: The specimen case Amalia X. In M. Leuzinger-Bohleber, M. Solms, \& S. E. Arnold (Eds.). Outcome research and the future of psychoanalysis. Clinicians and researchers in dialogue. (pp. 68-88). New York: Routledge.

Knobloch-Fedders, L. M., Elkin, I., \& Kiesler, D.J. (2015). Looking Back, looking Forward: A historical reflection on psychotherapy process research. Psychotherapy Research 25(4), 383-395. https://doi.org/10.1080/10503307.2014.906764

Krause, M., Altimir, C., Pérez, C., \& de la Parra, G. (2014). Generic Change Indicators in therapeutic processes with different outcomes. Psychotherapy Research, 25(5), 533-545. https://doi.org/10.1080/10503307.2014.935516.

Krause, M., de la Parra, G., Arístegui, R., Dagnino, P., Tomicic, A., Valdés, N., ... Ramírez, M.L. (2007). The evolution of therapeutic change studied through generis change indicators. Psychotherapy Research, 17, 673-689. https://doi. org/10.1080/10503300601158814

Krause, R., \& Merten, J. (1999). Affects, Regulation of Relationship, Transference and Countertransference. International Forum of Psychoanalysis, 8, 103-114. https:// doi.org/10.1080/080370699436429

Lambert, M. J., Hansen, N. B., Umpress, V., Lunnen, K., Okiishi, J., \& Burlingame, G. M. (1996). Administration and scoring manual for the OQ-45.2. Wilmington, DE: American Professional Credentialing Services.

Merten, J. (1997). Facial-affective behavior, mutual gaze, and emotional experience. Journal of Nonverbal Behavior, 21(3), 179-201. https://doi. org/10.1023/A:1024969514170

Merten, J. (2005). Facial microbehavior and the emotional quality of the therapeutic relationship. Psychotherapy Research, 15, 325-333. https://doi. org/10.1080/10503300500091272

Mitchell, S.A. (1988). Relational concepts in psychoanalysis. Cambridge, MA: Harvard University Press.

Norcross, J. C. (2011). Psychotherapy relationships that work: Evidence based responsiveness (2nd ed.). New York: Oxford University Press. https://doi.org/10.1093/ acprof:oSo/9780199737208.001.0001

Piper, W.E., Azim, H.F.A., Joyce, A.S., \& McCallum, M. (1991). Transference interpretations, therapeutic alliance, and outcome in short term individual psychotherapy. Archives of General Psychiatry, 48, 946-953. http://doi.org/10.1001/archpsyc.1991.01810340078010 
Rasting, M., \& Beutel, M. (2005). Dyadic affective interactive patterns in the intake interview as a predictor of outcome. Psychotherapy Research, 15(3), 188-198. https://doi.org/10.1080/10503300512331335039

Raudenbush, S. W., Bryk, A. S., Cheong, Y., Congdon, R., \& du Toit, M. (2004). HLM6: Linear and non-linear modeling. Chicago: Scientific Software International.

Rozmarin, E., Muran, J. C., Safran, J., Gorman, B., Nagy, J., \& Winston, A. (2008). Subjective and intersubjective analyses of the therapeutic alliance in a brief relational therapy. American Journal of Psychotherapy, 62(3), 313-328.

Safran, J. D. (2003). The relational turn, the therapeutic alliance, and psychotherapy research: Strange bedfellows or postmodern marriage? Contemporary Psychoanalysis, 39, 449-475. https://doi.org/10.1080/00107530.2003.10747215

Safran, J. D., \& Kraus, J. (2014). Alliance ruptures, impasses, and enactments: A relational perspective. Psychotherapy, 51, 381-387. https://doi.org/10.1037/ $\underline{\mathrm{a} 0036815}$

Safran, J. D., \& Muran, J, Ch. (2000). Negotiating the therapeutic alliance. A relational treatment guide. New York: The Guilford Press.

Safran, J. D., \& Muran, J. Ch. (2006). Has the concept of the therapeutic alliance outlived its usefulness? Psychotherapy: Theory, Research, Practice, Training, 43, 286291. https://doi.org/10.1037/0033-3204.43.3.286

Safran, J. D., Muran, J. C., Samstag, L. W., \& Winston, A. (2005). Evaluating alliance-focused intervention for potential treatment failures: A feasibility study and descriptive analysis. Psychotherapy: Theory, Research, Practice, Training, 42(4), 512-531. https://doi.org/10.1037/0033-3204.42.4.512

Sayette, M. A., Cohn, J. F., Wertz, J. M., Perrott, M. A., \& Parrott, D. J. (2001). A psychometric evaluation of the Facial Action Coding System for assessing spontaneous expression. Journal of Nonverbal Behavior, 25(3), 167 - 185. https://doi. org/10.1023/A:1010671109788 


\section{APPENDIX}

A. HLM Fixed Effects models of patient's display of emotions and social smile

\begin{tabular}{|c|c|c|c|c|c|c|c|c|c|}
\hline & & \multicolumn{2}{|r|}{ Anger } & \multicolumn{2}{|r|}{ Fear } & \multicolumn{2}{|c|}{ Happiness } & \multicolumn{2}{|c|}{ Social Smile } \\
\hline & & $O R$ & $\mathrm{Cl}(95 \%)$ & $O R$ & $\mathrm{Cl}(95 \%)$ & $O R$ & $\mathrm{Cl}(95 \%)$ & $O R$ & $\mathrm{Cl}(95 \%)$ \\
\hline \multirow[t]{4}{*}{ Model $^{\mathrm{a}}$} & Intercept & & & $0.01^{* * *}$ & $(0.002-0.023)$ & & & & \\
\hline & Fragile & & & 1.89 & $(0.186-19.155)$ & & & & \\
\hline & Type of episode & & & 1.51 & $(0.240-9.467)$ & & & & \\
\hline & $\begin{array}{l}\text { Fragile*Type of } \\
\text { episode }\end{array}$ & & & 44.15 & $(0.239-8164.441)$ & & & & \\
\hline \multirow[t]{4}{*}{ Model ${ }^{b}$} & Intercept & $0.03^{* * *}$ & $(0.019-0.051)$ & $0.01^{* * *}$ & $(0.002-0.024)$ & $0.08^{* * *}$ & $(0.035-0.172)$ & $0.05^{* * *}$ & $(0.020-0.117)$ \\
\hline & Questioning & 1.16 & $(0.248-5.404)$ & 0.82 & $(0.051-13.151)$ & 1.55 & $(0.376-6.402)$ & 1.13 & $(0.195-6.565)$ \\
\hline & Type of episode & $0.29^{*}$ & $(0.101-0.804)$ & 1.51 & $(0.251-9.060)$ & 0.41 & $(0.106-1.582)$ & 0.57 & $(0.135-2.425)$ \\
\hline & $\begin{array}{l}\text { Questioning*Type } \\
\text { of episode }\end{array}$ & 6.46 & $(0.802-52.095)$ & 1.35 & $(0.019-94.220)$ & 1.05 & $(0.117-9.482)$ & 0.72 & $(0.062-8.366)$ \\
\hline \multirow[t]{4}{*}{ Model $^{c}$} & Intercept & & & $0.00^{* * *}$ & $(0.001-0.017)$ & $0.08^{* * *}$ & $(0.037-0.184)$ & $0.05^{* * *}$ & $(0.021-0.124)$ \\
\hline & Propositive & & & $38.07^{* *}$ & $(4.047-358.145)$ & 0.47 & $(0.094-2.394)$ & 0.31 & $(0.050-1.878)$ \\
\hline & Type of episode & & & 4.70 & $(0.617-35.763)$ & 0.38 & $(0.084-1.731)$ & 0.44 & $(0.087-2.188)$ \\
\hline & $\begin{array}{l}\text { Propositive*Type } \\
\text { of episode }\end{array}$ & & & $0.00^{* * *}$ & $(0.000-0.112)$ & 2.32 & $(0.314-17.067)$ & 4.48 & $(0.527-38.026)$ \\
\hline \multirow[t]{4}{*}{ Model $^{d}$} & Intercept & & & & & $0.10^{* * *}$ & $(0.043-0.228)$ & $0.06^{* * *}$ & $(0.025-0.152)$ \\
\hline & Defensive & & & & & 0.51 & $(0.192-1.346)$ & 0.47 & $(0.157-1.383)$ \\
\hline & Type of episode & & & & & 0.38 & $(0.098-1.482)$ & 0.50 & $(0.116-2.125)$ \\
\hline & $\begin{array}{l}\text { Defensive*Type of } \\
\text { episode }\end{array}$ & & & & & 0.31 & $(0.020-4.730)$ & 0.41 & $(0.026-6.273)$ \\
\hline \multirow[t]{4}{*}{ Modele } & Intercept & & & & & $0.08^{* * *}$ & $(0.034-0.170)$ & $0.05^{* * *}$ & $(0.019-0.113)$ \\
\hline & Receptive & & & & & 1.76 & $(0.439-7.088)$ & 1.69 & $(0.371-7.732)$ \\
\hline & Type of episode & & & & & 0.45 & $(0.117-1.729)$ & 0.59 & $(0.140-2.506)$ \\
\hline & $\begin{array}{l}\text { Receptive*Type of } \\
\text { episode }\end{array}$ & & & & & 0.28 & $(0.012-6.553)$ & 0.38 & (0.016-9.058) \\
\hline
\end{tabular}

Model variability for Fear at Level-1 and Level-2 $s=2.53(p=.263)$, at Level-3 $s=2.04(p=.025)$.

${ }^{b}$ Model variability for: Anger at Level-1 and Level-2 $=0.13(p>.500)$, at Level-3 $s=0.29(p=.120)$; Fear at Level-1 and Level-2 $s=2.62(p=.236)$, at Level-3 s $=2.00(p=.029)$; Happiness at Level-1 and Level-2 s = $1.00(p=.016)$, at Level-3 s = 2.25 ( $p<.001)$; Social Smile at Level-1 and Level-2 $s=0.84(p>.500)$, at Level-3 s = 2.61 $(p<.001)$.

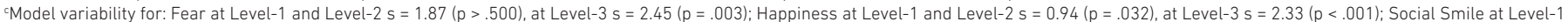
and Level-2 $\mathrm{s}=0.71(\mathrm{p}>.500)$, at Level-3 $\mathrm{s}=2.79(\mathrm{p}<.001)$

dModel variability for: Happiness at Level- 1 and Level- $2 s=0.85(p=.079)$, at Level-3 s = 2.29 ( $p<.001)$; Social Smile at Level-1 and Level-2 $s=0.71(p>.500)$, at Level-3 $s=2.65(p<.001)$

eModel variability for: Happiness at Level-1 and Level-2 $s=0.94(p=.034)$, at Level-3 s $=2.31(p<.001)$; Social Smile at Level-1 and Level-2 $s=0.82(p>.500)$, at Level-3 $s=2.65(p<.001)$.

${ }^{*} p<.05 ;{ }^{* *} p<.01 ; * * p<.001$ 
Pág 198

B. HLM Fixed Effects models of patient's facial display of regulatory behavior

\begin{tabular}{|c|c|c|c|c|c|c|c|c|c|}
\hline & & \multicolumn{2}{|r|}{ Gazing } & \multicolumn{2}{|c|}{ Self-soothing (Adaptors) } & \multicolumn{2}{|r|}{ Control } & \multicolumn{2}{|c|}{ Illustrators } \\
\hline \multirow[t]{4}{*}{ Modela $^{\mathrm{a}}$} & Intercept & $0.49^{* * *}$ & $(0.332-0.723)$ & & & & & & \\
\hline & Fragile & 0.83 & $(0.393-1.733)$ & & & & & & \\
\hline & Type of episode & $8.90^{* * *}$ & $(4.831-16.399)$ & & & & & & \\
\hline & $\begin{array}{l}\text { Fragile*Type of } \\
\text { episode }\end{array}$ & 0.17 & $(0.006-4.492)$ & & & & & & \\
\hline \multirow[t]{4}{*}{ Model $^{b}$} & Intercept & $0.55^{* *}$ & $(0.364-0.825)$ & $0.03^{* * *}$ & $(0.011-0.082)$ & $0.13^{* * *}$ & $(0.083-0.195)$ & $0.11^{* * *}$ & $(0.054-0.232)$ \\
\hline & Defensive & 0.64 & $(0.377-1.075)$ & 0.50 & $(0.128-1.968)$ & 0.56 & $(0.264-1.180)$ & 1.46 & $(0.516-4.118)$ \\
\hline & Type of episode & $8.46^{* * *}$ & $(4.502-15.906)$ & $4.91^{*}$ & $(1.138-21.155)$ & 0.72 & $(0.377-1.391)$ & 1.08 & $(0.348-3.374)$ \\
\hline & $\begin{array}{l}\text { Defensive *Type } \\
\text { of episode }\end{array}$ & 0.55 & $(0.135-2.280)$ & 0.29 & $(0.007-12.157)$ & 1.32 & $(0.159-10.983)$ & 1.37 & $(0.098-19.208)$ \\
\hline \multirow{2}{*}{ Model ${ }^{c}$} & Type of episode & $10.08^{* * *}$ & $(5.462-18.619)$ & & & 0.87 & $(0.456-1.667)$ & 0.96 & $(0.330-2.767)$ \\
\hline & $\begin{array}{l}\text { Receptive *Type } \\
\text { of episode }\end{array}$ & $0.04^{* *}$ & $(0.006-0.307)$ & & & 1.03 & $(0.084-12.811)$ & 3.19 & $(0.199-51.250)$ \\
\hline \multirow[t]{4}{*}{ Model $^{d}$} & Intercept & $0.47^{* * *}$ & $(0.322-0.674)$ & 0.02 & $(0.008-0.053)$ & $0.11^{* * *}$ & $(0.072-0.161)$ & $0.13^{* * *}$ & $(0.065-0.246)$ \\
\hline & Questioning & 1.38 & $(0.664-2.863)$ & 4.07 & $(0.941-17.578)$ & 0.87 & $(0.297-2.552)$ & 0.91 & $(0.217-3.845)$ \\
\hline & Type of episode & $8.52^{* * *}$ & $(4.681-15.495)$ & $7.57^{* *}$ & $(1.905-30.050)$ & 0.78 & $(0.406-1.516)$ & 0.95 & $(0.314-2.867)$ \\
\hline & $\begin{array}{l}\text { Questioning*Type } \\
\text { of episode }\end{array}$ & 1.58 & $(0.399-6.242)$ & $0.02^{*}$ & $(0.001-0.749)$ & 2.02 & $(0.368-11.118)$ & 1.90 & $(0.152-23.698)$ \\
\hline Model $^{e}$ & Intercept & $0.44^{* * *}$ & $(0.299-0.647)$ & $0.02^{* * *}$ & $(0.009-0.064)$ & $0.10^{* * *}$ & $(0.067-0.149)$ & $0.13^{* * *}$ & $(0.069-0.251)$ \\
\hline \multirow{2}{*}{ Model $^{f}$} & Type of episode & $9.79^{* * *}$ & $(5.179-18.496)$ & $6.52^{*}$ & $(1.457-29.140)$ & 0.79 & $(0.398-1.572)$ & & \\
\hline & $\begin{array}{l}\text { Conciliator }{ }^{*} \text { Type } \\
\text { of episode }\end{array}$ & 0.28 & $(0.040-1.985)$ & $0.03^{*}$ & $(0.001-0.891)$ & 1.00 & $(0.076-13.082)$ & & \\
\hline
\end{tabular}

a Model variability for: Gazing at Level-1 and Level-2 $s=0.46(p<.001)$, at Level-3 $s=0.40(p<.0001)$.

Model variability for: Gazing at Level-1 and Level-2 s = $0.41(p<.001)$, at Level-3 s = $0.41(p<.001)$; Adaptors at Level-1 and Level-2 s = 2.49 ( $p<.001)$, at Level-3 s = 2.16 ( $p<.001)$; Control at Level-1 and Level-2 $s=0.89(p<.001)$, at Level-3 $s=0.13(p=.095)$; Illustrator at Level-1 and Level-2 $s=2.81(p<.001)$, at Level-3 $s=0.93(p=.002)$.

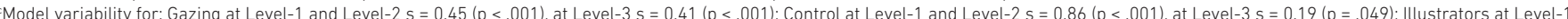
and Level-2 $s=2.82(p<001)$, at Level-3 $s=0.83(p=.005)$

Model variability for: Gazing at Level-1 and Level-2 s = $0.46(p<.001)$, at Level-3 s = $0.36(p<.001)$; Adaptors at Level-1 and Level-2 s = 2.51 ( $p<.001)$, at Level-3 s = 1.83 ( $p<.001)$; Control at Level-1 and Level-2 $s=0.87(p<.001)$, at Level-3 s = $0.18(p=.057)$; Illustrators at Level-1 and Level- $2 s=2.81(p<.001)$, at Level-3 $s=0.94(p=.002)$.

Model variability for: Gazing at Level-1 and Level-2 s = $0.33(p<.001)$, at Level-3 s=0.47 ( $p<.001)$; Adaptors at Level-1 and Level-2 s = 2.50 ( $p<.001)$, at Level-3 s $=2.24(p<.001)$; Control at Level-1 and Level-2 $s=0.81(p<.001)$, at Level-3 $s=0.20(p=.034)$ : Illustrators at Level-1 and Level-2 $s=2.80(p<.001)$, at Level-3 $s=0.88(p=003)$.

'Model variability for: Gazing at Level-1 and Level-2 $s=0.44(p<.001)$, at Level-3 s = $0.42(p<.001)$; Adaptors at Level-1 and Level-2 s = 2.40 ( $p<.001)$, at Level-3 $s=2.27$ ( $p<.001)$ : Control at Level-1 and Level-2 $s=0.85(p<.001)$, at Level-3 $s=0.21(p=.038)$

${ }^{*} p<.05 ;{ }^{* *} p<.01 ;{ }^{* *} p<.001$ 
Pág 199

C. HLM Fixed Effects models of therapist's facial display of emotions and social smile

\begin{tabular}{|c|c|c|c|c|c|c|c|}
\hline & & \multicolumn{2}{|c|}{ Sadness } & \multicolumn{2}{|c|}{ Happiness } & \multicolumn{2}{|c|}{ Social Smile } \\
\hline & & OR & $\mathrm{Cl}(95 \%)$ & OR & $\mathrm{Cl}(95 \%)$ & OR & $\mathrm{Cl}(95 \%)$ \\
\hline \multirow[t]{4}{*}{ Modela $^{\mathrm{a}}$} & Intercept & $0.03^{* * *}$ & $(0.012-0.055)$ & $0.11^{* * *}$ & $(0.057-0.211)$ & & \\
\hline & Receptive & 1.63 & $(0.226-11.834)$ & 2.24 & $(0.664-7.577)$ & & \\
\hline & Type of episode & 1.25 & $(0.399-3.921)$ & 1.09 & $(0.399-3.003)$ & & \\
\hline & Receptive *Type of episode & 1.66 & $(0.059-46.590)$ & 1.15 & $(0.113-11.721)$ & & \\
\hline \multirow[t]{4}{*}{ Model $^{b}$} & Intercept & $0.03^{* * *}$ & $(0.012-0.058)$ & $0.12^{* * *}$ & $(0.061-0.227)$ & $0.03^{* * *}$ & $(0.017-0.062)$ \\
\hline & Questioning & 0.95 & $(0.138-6.519)$ & 1.13 & $(0.345-3.704)$ & 1.39 & $(0.286-6.732)$ \\
\hline & Type of episode & 1.04 & $(0.313-3.448)$ & 1.15 & $(0.411-3.222)$ & 2.31 & $(0.901-5.903)$ \\
\hline & Questioning*Type of episode & 3.75 & $(0.226-62.404)$ & 0.38 & $(0.047-3.043)$ & 0.29 & $(0.023-3.673)$ \\
\hline \multirow[t]{4}{*}{ Model $^{c}$} & Intercept & & & $0.11^{* * *}$ & $(0.055-0.223)$ & $0.03^{* * *}$ & $(0.016-0.068)$ \\
\hline & Defensive & & & 1.27 & $(0.527-3.077)$ & 1.07 & $(0.353-3.230)$ \\
\hline & Type of episode & & & 1.17 & $(0.410-3.355)$ & 2.15 & $(0.809-5.719)$ \\
\hline & Defensive ${ }^{*}$ Type of episode & & & 0.34 & $(0.027-4.448)$ & 0.41 & $(0.022-7.541)$ \\
\hline \multirow[t]{4}{*}{ Model $^{d}$} & Intercept & & & $0.13^{* * *}$ & $(0.064-0.248)$ & $0.03^{* * *}$ & $(0.018-0.061)$ \\
\hline & Propositive & & & 0.22 & $(0.043-1.111)$ & 1.96 & $(0.342-11.256)$ \\
\hline & Type of episode & & & 0.69 & $(0.201-2.374)$ & 1.45 & $(0.457-4.592)$ \\
\hline & Propositive *Type of episode & & & $8.69^{*}$ & $(1.269-59.424)$ & 0.95 & $(0.118-7.611)$ \\
\hline
\end{tabular}

aModel variability for: Sadness at Level-1 and Level-2 $s=2.02(p=.065)$, at Level-3 $s=0.82(p=.034) ;$ Happiness at Level-1 and Level-2 $s=1.30(p<.001)$, at Level-3 $s=1.18(p<.001)$. ${ }^{b}$ Model variability for: Sadness at Level-1 and Level-2 $s=2.00(p=.126)$, at Level-3 s $=0.94(p=.019)$; Happiness at Level-1 and Level-2 $s=1.34(p<.001)$, at Level-3 $s=1.23(p<.001) ;$ Social Smile at Level- 1 and Level-2 $\mathrm{s}=1.43(\mathrm{p}=.023)$, at Level-3 $\mathrm{s}=0.55(\mathrm{p}=.018)$

${ }^{c}$ Model variability for: Happiness Level-1 and Level- $2 \mathrm{~s}=1.41(p<.001)$, at Level-3 $\mathrm{s}=1.17(p<.001)$ : Social Smile at Level-1 and Level-2 $\mathrm{s}=1.52(p=.014)$, at Level-3 $\mathrm{s}=0.48(p=.040)$.

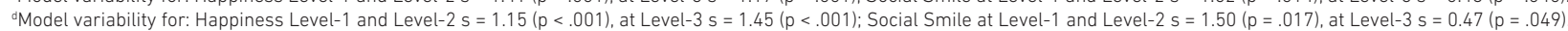
${ }^{*} p<.05 ;{ }^{* *} p<.01 ;{ }^{* * *} p<.001$. 
Pág 200

D. HLM Fixed Effects models of therapist's facial display of regulatory behavior

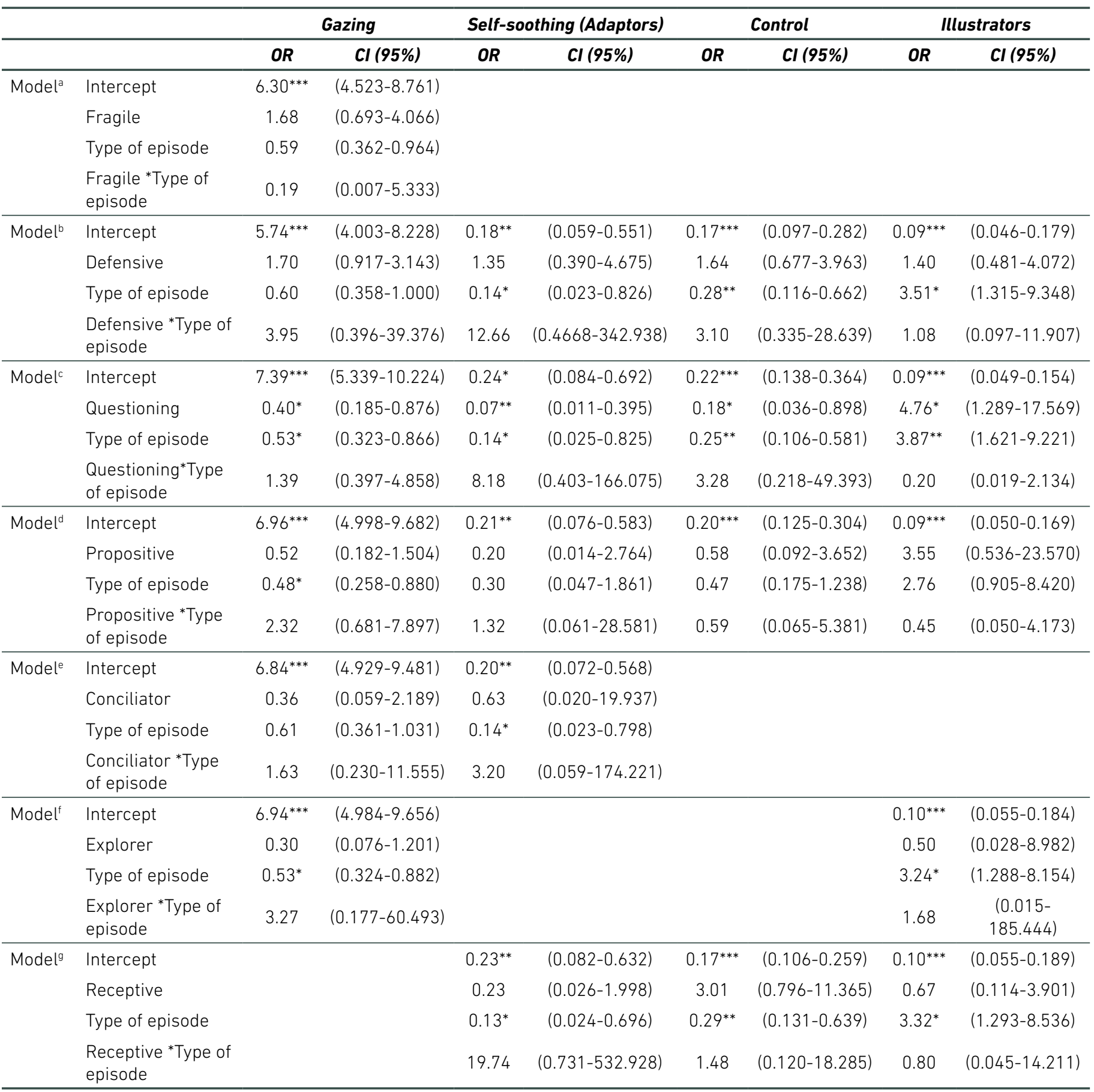

Model variability for: Gazing at Level-1 and Level- $2 \mathrm{~s}=0.54(p<.001)$, at Level-3 $s=0.09(p=.070)$.

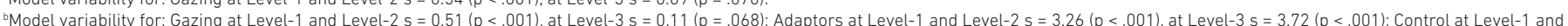
Level-2 $s=2.31(p<.001)$, at Level-3 $s=0.13(p=.124)$; Illustrators at Level-1 and Level- $2 \mathrm{~s}=3.10(p<.001)$, at Level-3 $\mathrm{s}=0.39(p=.081)$.

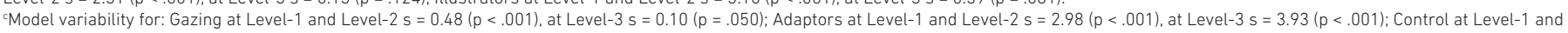
Level-2 $s=2.26(p<.001)$, at Level-3s $=0.21(p=.090)$; Ilustrators at Level-1 and Level-2 $s=3.07(p<.001)$, at Level-3 s = $0.19(p=.232)$.

${ }^{d}$ Model variability for: Gazing at Level-1 and Level-2 s = $0.50(p<.001)$, at Level-3 s = $0.13(p=.037)$; Adaptors at Level-1 and Level-2 $s=3.22$ ( $\left.p<.001\right)$, at Level-3 $s=3.54$ ( $\left.p<.001\right)$; Control at Level-1 and Level-2 $s=2.36(p<.001)$, at Level-3 $s=0.07(p=.162)$; Illustrators at Level-1 and Level-2 $s=3.03(p<.001)$, at Level- $3 s=0.44(p=.057)$.

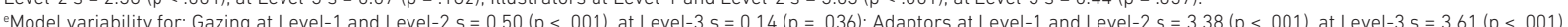

'Model variability for: Gazing at Level-1 and Level-2 $s=0.49(p<.001)$, at Level-3 $s=0.14(p=.027)$; Illustrators at Level-1 and Level- $2 \mathrm{~s}=3.08$ ( $p<.001)$, at Level-3 $\mathrm{s}=0.44$ ( $p=.058$ ).

9Model variability for: Adaptor at Level-1 and Level-2 $s=3.35(p<.001)$, at Level-3 s=3.37 ( $<<.001)$; Control at Level-1 and Level-2 $s=2.46(p<.001)$, at Level-3 $s=0.01(p=.222)$; Illustrators at Level-1

and Level-2 $s=3.09(p<.001)$, at Level-3 $s=0.45(p=.055)$.

${ }^{*} \mathrm{p}<.05 ;{ }^{* *} \mathrm{p}<.01:{ }^{* * *} \mathrm{p}<.001$ 